\title{
Investigation of hybridized composite pressure vessel
}

\author{
S. Irfan Sadaq ${ }^{1}$, Shaik Khadar Vali ${ }^{2}$, Shaik Imran Sharif ${ }^{3}$ \\ ${ }^{1}$ Assistant Professor, Mech. Engg. Department, Muffakham Jah College of Engineering \& Technology, Hyderabad, Telangana, India \\ ${ }^{2}$ Professor, Mech. Engg. Department, Muffakham Jah College of Engineering \& Technology, Hyderabad, Telangana, India \\ ${ }^{3}$ PG Student, Mech. Engg. Department, Muffakham Jah College of Engineering \& Technology, Hyderabad, Telangana, India
}

\begin{abstract}
Burst pressure is the vital parameter to be strong-minded for their design. Burst pressure is the pressure at which vessel crack and core fluid seep outs. A design shelterbound that ought to not be surpassed. Further than this pressure possibly willescort to mechanical fall foul of and enduring loss of pressure restraint. The present work is aimed in studying the pressure vessel (PV) made with composite material. During the study the PV is fabricated by glass fiber with $90^{\circ}$ fiber angle and performed hydrostatic test. Later the same PV is modeled in Ansys and analyzed with various fiber angles to determine the failure by considering their deformation, stress and strain of the PV using GFRP, CFRP and hybrid composites. At last the results obtained are validated.
\end{abstract}

\section{INTRODUCTION}

A pressure vessel playsa very important role as they are used to store many liquids under high pressure. Special emphasis should be given to the strength of the pressure vessel to prevent explosions as a result of rupture. Standard Codes have been developed for the safety of such vessels that specify the design of the container for specified conditions. Some of the pressure vessels has to carry high pressures, and therefore thickness of the vessel walls must increase in order to provide adequate strength. Interest in studying of the shell arises from the fifties of twentieth century. The assemblies for thin shells find wide use in the modern engineering, especially in ships, aircraft and spacecraft industry. From households to industrial to aviation Composite pressure vessels find application in various fields. Due to pressure differential their failure may lead to fatal accidents therefore, they are critical component in various systems. Burst pressure is the important parameter to be determined for their design. Burst pressure is the pressure at which vessel burst/crack and internal fluid leaks. It is a design safety limit that should not be exceeded. Exceeding this pressure may lead to mechanical breach and permanent loss of pressure containment. Many studies and research works were carried out by various researchers for the better understanding of structural performance of laminated composite pressure vessels. Cylindrical shells such as thin walled laminated composite unstiffened vessels like deep submarine exploration housings and autonomous underwater vehicles are subjected to any combination of in plane, Out of plane and shear loads due to the high external hydrostatic pressure during their application. Due to the geometry of these structures, buckling is one of the most important failure criteria.

\section{LITERATURE REVIEW}

Reshma Ramesh et. al.(2017) [1] For safety reasons it is important to know the burst pressure of pressure vessels for operations. In this paper, a review on research work carried out for laminated composite pressure vessel. Avoiding use of analytical approach to avoid unnecessary conservatism. Proper fiber orientation and laminate thickness is very important to decrease manufacturing difficulties and increase structural efficiency.M. Nebe et. al.(2020) [2] The analysis of composite pressure vessels for the mechanical response during internal pressure loading through the correlation of numerical and experimental results on various degrees of complexity had been done. The correlation established in this work confirms that a comprehensive knowledge of the vessel's meridional thickness profile and the determination of representative material properties permit to realistically reproduce the mechanical response and final strength of composite pressure vessels by means of finite element analysis.Durga Prasanth et. al.(2019) [3] Design of a pressure vessel according to ASME standards. Variation in shell thickness, use of different types of materials and thermal analysis is done for ambient temperatures. For the crack present fracture mechanics is used to analyze the geometries of the crack with different materials. The maximum crack tip deformation is found in case of Aluminum due to its high elastic properties and the lowest in the case of ASME material.

Merlin J. Thattil et. al.(2017) [4] pressure vessel with different end domes i.etorispherical and hemispherical, have been designed for a volume of 1000 liters subjected to internal pressure for space application. Based on the

\footnotetext{
* Corresponding author: irfan.sadaq@mjcollege.ac.in, khadar.vali@mjcollege.ac.in, 160419765010@mjcollege.ac.in
} 
analysis, optimum thickness which meets the strength requirement of the material had been determined. A stress at the junction of torispherical head to cylindrical shell is lower than hemispherical domes. Fabrication of torispherical pressure vessel is much easier.Mr. Ravi Krishnamoorthy et. al.(2017) [5] Pressure vessel for fatigue loading had been analyzed. By using Miner's law cumulative usage of fatigue factor are investigated to determine the adequacy of the design. The methodology is to perform fatigue analysis on a typical pressure vessel to ASME. Stress concentration factor is one of the most important factors affecting the fatigue usage factor. Subhash N. Khetre et. al. (2014) [6] Material used are aluminum and fiber matrix. FEA software for failure analysis on the composite shell of continuous angle ply laminas. Tsai-Wu failure criterion is applied for the checking the first-ply failure of layers in a simple form. T-Sai Wu failure criteria can yield fairly good results with consistent accuracy for the composite pressure vessels.Abhijit Dey et. al.(2014) [7] Investigate the post buckling behaviour of moderately thick-walled filamentwound carbon- epoxy composite cylinders under external hydrostatic pressure through finite element analysis for under water vehicle applications. ANSYS shell element model predicted the buckling pressure with $1.5 \%$ deviation from the other three finite element results and experimental results, not considering the initial imperfections of the cylinders.

Kuran et. al.(2017) [8] The main efforts are made for this paper to design the pressure vessel for application by using ASME codes \& standards to prove the design. As the ASME code provides all basic detail data regarding design so it's very important to minimize the design time with proper analysis. By using ASME code we can avoid the over design and material cost with optimum design.G. Romeo et. al.(2013) [9]A parametric analysis has been performed to define the optimum layout and the number of tanks necessary to supply the required power. Genetic algorithm has been used to optimize the laminate layup in order to reduce the weight of the tank and ensure that it can resist without failing catastrophically. Validation shows a good correlation between the experimental and the FE results. The optimized stack sequence has in fact shown a notable presence of almost $0^{\circ}$ plies in order to ensure an appropriate bending stiffness.S. Elangovan et. al.(2013) [10] Corrosion forming over the life of a storage tank is catered for by a corrosion limit, the design value of which depends upon the storage tank duty and the corrosiveness of its content. In this project, an attempt has been made to find ways of decreasing corrosiveness/rust of the pressure vessel accordingly increasing the life of pressure vessel by applying coatings to the pressure vessels.

\section{METHODOLOGY}

\section{A. Experimentation}

Fabrication of pressure vessel used for oxygen cylinder was done by hand layup technique. In this method Glass
/Epoxy material is wrapped with the suitable thickness as mentioned in the table1. Each layer thickness is $1 \mathrm{~mm}$, and total 12 layers of glass/epoxy fibres were wrapped on a cylindrical mould and boned strongly. One end of the cylinder is opened with $24 \mathrm{~mm}$ as diameter to insert nozzle for filling oxygen. Hydrostatic test is performed to study the behaviour the cylinder.

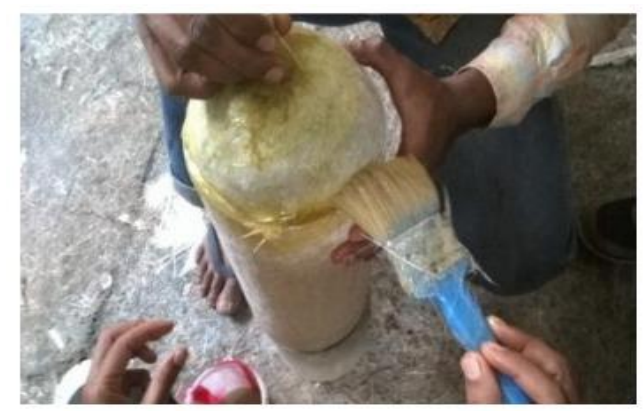

Fig.1: Fabrication of PV Cylinder

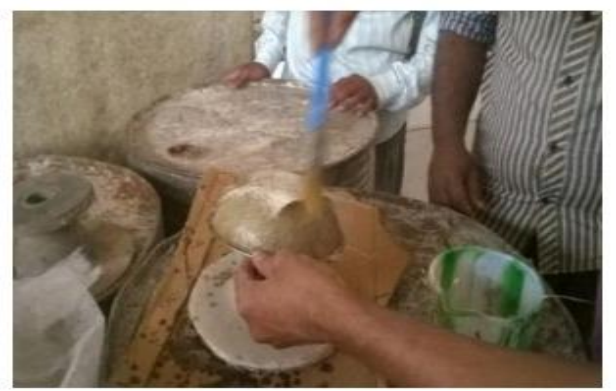

Fig.2: Applying Resin for modul

Table 1: Dimensions of the PV Cylinder

\begin{tabular}{|l|l|}
\hline Specifications & Units (mm) \\
\hline Outer dia. & 350 \\
\hline Inner dia. & 326 \\
\hline Length & 1000 \\
\hline Radius opening & 12 \\
\hline Thickness & 12 \\
\hline
\end{tabular}

\section{B. Procedure of the hydrostatic test}

Cylinder fabricated was tested to study the behaviour, based on this and keeping safety factor, hydrostatic test was performed by following all the norms of safety. The water is first filled and later pressure is applied. Gradually pressure is increased andkept on hold for 3 minutes as shown in fig.3..For each and every step using dial gauge the deformation is noted and inspected.

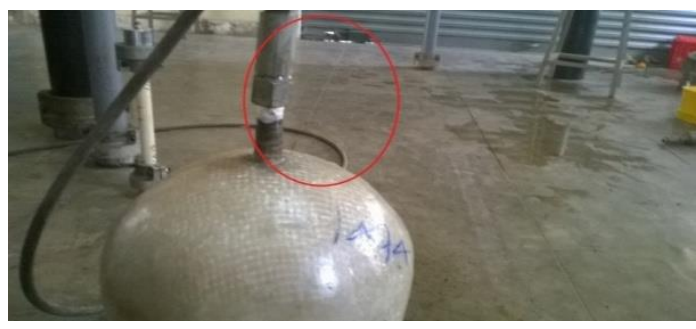

Fig.3: Testing of GFRP PV 
Table 2: Testing results of PV Cylinder at various pressure

\begin{tabular}{|c|c|c|}
\hline $\begin{array}{l}\text { Pressure } \\
\text { applied } \\
\text { (Bar) }\end{array}$ & $\begin{array}{l}\text { Embrace } \\
\text { Time } \\
\text { (minutes) }\end{array}$ & Commentary \\
\hline 17 & 3 & - \\
\hline 30 & 3 & - \\
\hline 36 & 3 & - \\
\hline 42 & 3 & At valve Interface \\
\hline 48.8 & 3 & Crack propagation started at \\
the interface.
\end{tabular}

Table 3: Deformation values at every loading step

\begin{tabular}{|l|l|}
\hline $\begin{array}{l}\text { Pressure } \\
\text { applied } \\
\text { (Bar) }\end{array}$ & Deformation (mm) \\
\hline 17 bar & 0.3708 \\
\hline 30 bar & 0.4031 \\
\hline 36 bar & 0.4382 \\
\hline 42 bar & 0.4763 \\
\hline 48.8 bar & 0.5177 \\
\hline 54 bar & 0.5627 \\
\hline
\end{tabular}

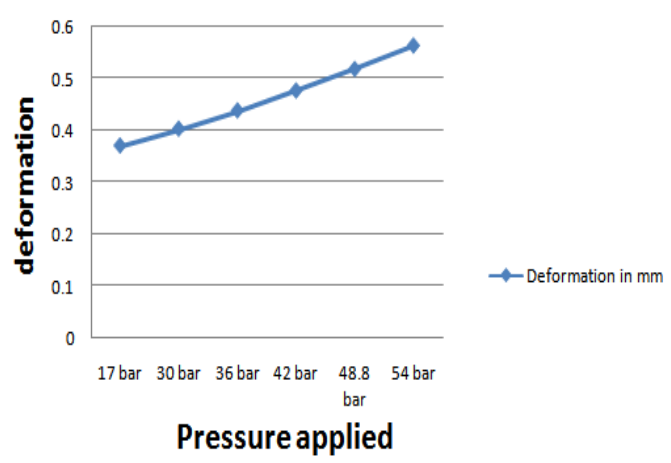

Fig.4: Deformation obtained during experimentation for GFRP $\mathrm{PV}$ at various pressures

\section{ANALYSIS using Ansys Software}

Analysis was done in ANSYS APDL and different angle orientations are determined to check which is best and validate the results.Pressure value obtained from experimentation results is used for analysis i.e. 54 bar(5.4 MPa).This pressure value of 5.4 MPa was used as an input in analysis of pressure vessel in Ansys APDL.

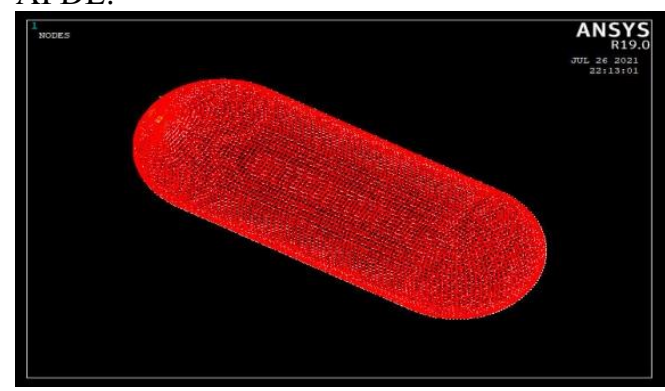

Fig.5: Ansys APDL view of composite pressure vessel.

\section{RESULTS AND DISCUSSION}

Composite pressure vessel made with glass fiber is fabricated with dimension as mentioned above in table 1 , and tested. The fiber angle of PV during testing was $90^{\circ}$. Hydrostatic test is carried out to determine the failure of the PV at various pressures. The failure of the PV was occurred at 54 bars. The PV with same dimensions is modelled in Ansys to analyse them with various fiber angles. The angles chosen are $0^{\circ}, 30^{\circ}, 45^{\circ}, 60^{\circ}, \& 90^{\circ}$. The results experimental and Ansys were validated future.

Table 4: Deformation at GFRP pressure vessel at 54 bar (5.4MPa)

\begin{tabular}{|c|c|c|}
\hline $\begin{array}{l}\text { Deformation } \\
(\mathrm{mm}) \\
\text { Experimentation }\end{array}$ & $\begin{array}{l}\text { Deformation } \\
\text { (mm) } \\
\text { Ansys }\end{array}$ & Validation \\
\hline 0.5627 & 0.6116 & $8 \%$ \\
\hline
\end{tabular}

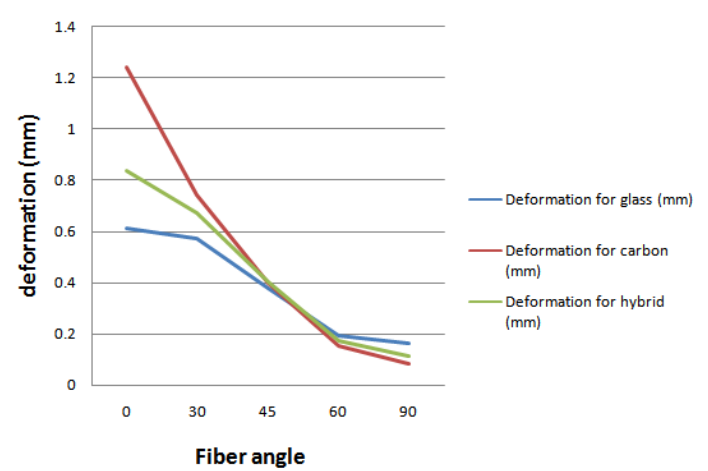

Fig.6: Graph, deformation of PV (Glass fiber, Carbon fiber and Hybrid fibers) at various fiber angles in Ansys

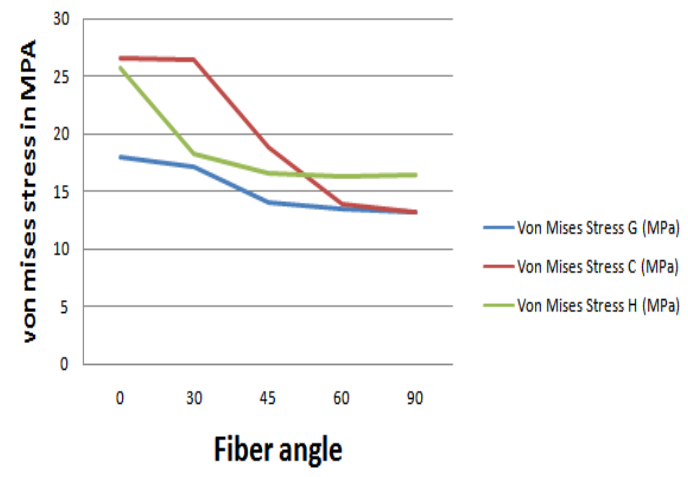

Fig.7: Graph, Vonmises Stress of PV (Glass fiber, Carbon fiber and Hybrid fibers) at various fiber angles in Ansys 


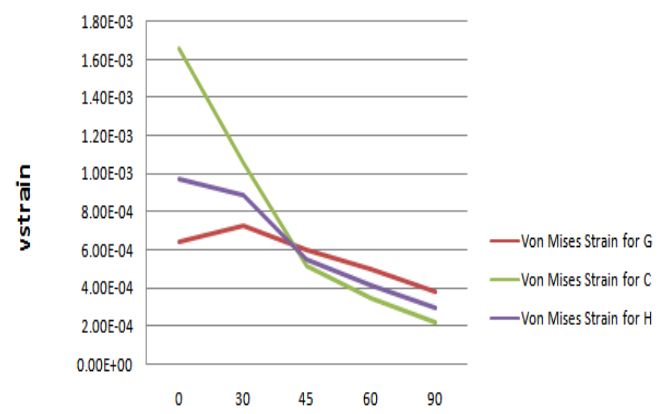

Fiber angle

Fig.8: Graph, Vonmises Strain of PV (Glass fiber, Carbon fiber and Hybrid fibers) at various fiber angles in Ansys

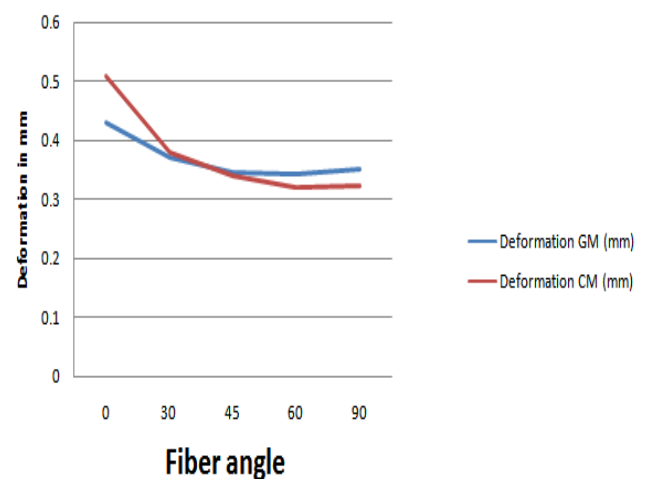

Fig.9: Graph, deformation of PV made with Mild steel and inner layer with composite material at various fiber angles in Ansys

\section{CONCLUSION}

During, analysis using Ansys for mild steel deformation value obtained is $0.20303 \mathrm{~mm}$ at $5 \mathrm{~mm}$ thickness. Deformation for glass fiber, carbon fiber and hybrid fibers is optimum at $90 \mathrm{deg}$. with less value of deformation for carbon fiber equal to $0.0841 \mathrm{~mm}$ which is lesser than steel at $12 \mathrm{~mm}$ thickness.Considering strength von mises stress value for glass, carbon and hybrid is optimum at 0 deg. i.e. stress value of Carbon fiber is high to be $26.5551 \mathrm{MPa}$.It can be concluded that carbon fiber is suitable material for fabrication of pressure vessel but since cost of carbon fiber is high,therefore hybrid composite material maybe used which yields better results than mild steel. These composite are light weighted Even though the thickness of the cylinder is twice or thrice of Mild steel. To improve the durability of the cylinder made there is necessity for shifting the material from tradition to composite materials.

\section{References}

[1]. Reshma Ramesh., Asha Joseph. International Research Journal of Engineering and Technology (IRJET). 4, 2738 (2017).
[2]. Nebe M, Soriano A, Braun C, Middendorf P, Walther F. Composites Part B: Engineering. 108550 (2020).

[3]. DURGA PRASANTH, SACHIDANANDA. H. K. International Journal of Mechanical and Production Engineering Research and Development (IJMPERD)-Vol. 9, (2019).

[4]. Thattil MJ, Pany C. International Journal of Science, Engineering and Technology Research.; 6, 1225 (2017).

[5]. Deepak MR, Bhardwaj TS. International Journal of Theoretical and Applied Mechanics; 12, 769 (2017).

[6]. Subhash N. Khetre, P. T. Nitnaware, Arun Meshram, International Journal of Engineering Research \& Technology (IJERT), 3 (2014).

[7]. Abhijit Deya , Gaurav Chaudharyb , P.L. Choudhuryc, K.M. Pandeyd. International Journal of Trends in Economics, Management and Technology, 3 (2014).

[8]. Kuran, Narayangoan. International Journal for Scientific Research \& Development (IJSRD), 5 (2017)

[9]. G. Romeo , F. Danzi, E. Cestino, F. Borello. International Journal of Aerospace Sciences, 2, 124 (2013).

[10]. S. Elangovan, S. Karthikeyan, Rajesh. Global Research and Development Journal for EngineeringGRD Journals, 4 (2019). 